\title{
Cognitive impairment and stroke in elderly patients
}

\author{
This article was published in the following Dove Press journal: \\ Vascular Health and Risk Management \\ 24 March 2016 \\ Number of times this article has been viewed
}

\section{Daniele Lo Coco' \\ Gianluca Lopez' \\ Salvatore Corrao ${ }^{2,3}$ \\ 'Neurology and Stroke Unit, 2Department of Internal Medicine, National Relevance and High Specialization Hospital Trust ARNAS \\ Civico, Di Cristina, Benfratelli, Palermo, ${ }^{3}$ Centre of Research for Effectiveness and Appropriateness in Medicine (C.R.E.A.M.), Di.Bi.M.I.S., University of Palermo, Palermo, Italy}

Correspondence: Salvatore Corrao Dipartimento Biomedico di Medicina Interna e Specialistica (Di.Bi.M.I.S.), University of Palermo, Piazza delle Cliniche, 2, 90I 27 Palermo, Italy Tel +39 09। 6552065

Fax +3909I 6663167

Email s.corrao@tiscali.it
Abstract: We reviewed current knowledge about the interaction between stroke and vascular risk factors and the development of cognitive impairment and dementia. Stroke is increasingly recognized as an important cause of cognitive problems and has been implicated in the development of both Alzheimer's disease and vascular dementia. The prevalence of cognitive impairment after stroke is high, and their combined effects significantly increase the cost of care and health resource utilization, with reflections on hospital readmissions and increased mortality rates. There is also substantial evidence that vascular risk factors (such as hypertension, diabetes, obesity, dyslipidemia, and tobacco smoking) are independently associated with an increased risk of cognitive decline and dementia. Thus, a successful management of these factors, as well as optimal acute stroke management, might have a great impact on the development of cognitive impairment. Notwithstanding, the pathological link between cognitive impairment, stroke, and vascular risk factors is complex and still partially unclear so that further studies are needed to better elucidate the boundaries of this relationship. Many specific pharmacological treatments, including anticholinergic drugs and antihypertensive medications, and nonpharmacological approaches, such as diet, cognitive rehabilitation, and physical activity, have been studied for patients with vascular cognitive impairment, but the optimal care is still far away. Meanwhile, according to the most recent knowledge, optimal stroke care should also include cognitive assessment in the short and long term, and great efforts should be oriented toward a multidisciplinary approach, including quality-of-life assessment and support of caregivers.

Keywords: cerebrovascular disease, dementia, vascular risk factors, cognitive function, aging

\section{Introduction}

Both dementia and stroke represent growing social, health care, and economic problems. It is estimated that there were $>35$ million persons worldwide with dementia in 2010, and this number is expected to double every 20 years, ${ }^{1}$ largely due to an aging population and also an increasing prevalence of risk factors for dementia. The most common form of dementia is Alzheimer's disease (AD: $50 \%-75 \%$ ) followed by vascular dementia (VaD: 20\%), dementia with Lewy bodies (5\%), and frontotemporal dementia (5\%). The major risk factor for the development of dementia is increasing age. $^{2}$ Other known risk factors include family history, low levels of physical activity and education, and the presence of epsilon 4 allele of the apolipoprotein $\mathrm{E}$ ( $A P O E \varepsilon 4)$ gene. ${ }^{3}$ However, over the past 15-20 years, a growing body of literature has highlighted the significant contribution of stroke and vascular risk factors (such as hypertension, diabetes, obesity, dyslipidemia, hyperhomocysteinemia, and tobacco smoking) in the development of cognitive decline and dementia. ${ }^{3}$ 
Stroke is the second leading cause of death worldwide and the third most common cause of disability, ${ }^{4}$ generating expenses of $\sim \$ 30$ billion per year in direct costs and loss of productivity in the United States alone. Overall in 2010, an estimated 16.9 million cases of incident stroke took place worldwide, not to mention the 33.0 million prevalent stroke cases. ${ }^{4}$ The incidence of stroke increases with age, with up to $69 \%$ of individuals older than 65 years and a prevalence of $34.4 \%$ older than 75 years. ${ }^{4}$ Vascular disease is a significant predictor of the likelihood of hospital readmission in elderly patients. ${ }^{5}$

Dementia and stroke often occur together, and their combined effects significantly increase the cost of care and health resource utilization, with reflections on hospital readmissions and increased mortality rates, ${ }^{6-8}$ thus highlighting the need to investigate the relationship between these two conditions. However, apart from the occurrence of a clinical stroke, the mechanisms by which vascular factors increase the risk of dementia or accelerate cognitive deterioration among patients with AD remains largely unclear. Notwithstanding, early identification and correct medical treatment of cardiovascular conditions can reduce the prevalence of cognitive impairment and $\mathrm{AD}$, and, in this respect, prevention of dementia may be more effective than current pharmacological treatment. ${ }^{9,10}$ It has been estimated that delaying the onset of $\mathrm{AD}$ by just 1 year would lead to nine million fewer cases by $2050,{ }^{11}$ and if the age at onset of clinical dementia could be delayed in all cases by just 5 years, the lifetime risk of dementia could be drastically reduced. ${ }^{12}$ According to these observations, many recent studies have been published suggesting that the incidence of dementia and AD may have decreased over the past 2 decades, ${ }^{13-15}$ and the mortality improvements have been attributed to better awareness of cardiovascular disease risk factors. ${ }^{16}$ Moreover, successful management of hypertension and increase in the use of statins and antithrombotic drugs may have also played a significant role.

In this paper, we aimed to review current knowledge about the interaction between stroke and vascular risk factors and the development of cognitive impairment and dementia, with emphasis on pharmacological and nonpharmacological treatment and enhanced patient care.

\section{Management issues of stroke in elderly patients \\ Primary prevention}

Given the high rates of mortality and disability associated with stroke occurrence, management of significant risk factors is of paramount importance. Risk factors for stroke are usually divided into nonmodifiable and modifiable ones (Table 1). Nonmodifiable risk factors include age, sex, ethnicity, family history, and genetic predisposition. Modifiable risk factors include hypertension, diabetes, dyslipidemia, atrial fibrillation, obesity, smoking, and physical inactivity. A detailed description of the interventions recommended for the management of stroke risk factors is out of the scope of this review, and the reader is referred elsewhere for the details. ${ }^{17}$ However, it is worthwhile underlying that the treatment of hypertension is the most important intervention for primary and secondary preventions of ischemic stroke with blood pressure targets of a systolic pressure $<140 \mathrm{mmHg}$ and diastolic pressure $<90 \mathrm{mmHg},{ }^{17}$ even if some further benefit has been evidenced at systolic blood pressure $<130 \mathrm{mmHg} .{ }^{18}$ Obviously, the antihypertensive therapy has to be considered in conjunction with lifestyle modifications (including salt restriction, weight loss, the consumption of a diet rich in fruits, vegetables, low-fat dairy products, regular aerobic physical activity, and limited alcohol consumption). ${ }^{17}$ The use of antiplatelet agents for primary prevention is still debated, and there is no evidence that antiplatelet medications reduce the risk of stroke in the general population at low risk. ${ }^{17}$

Table I Risk factors for stroke

\begin{tabular}{ll}
\hline Nonmodifiable risk factors & Modifiable risk factors \\
\hline Age & Hypertension \\
Sex & Diabetes \\
Low birth weight & Dyslipidemia \\
Race/ethnicity & Obesity \\
Family history (including intracranial & Metabolic syndrome \\
aneurysms) & Diet and nutrition \\
Genetic predisposition (including Fabry & Cigarette smoking \\
disease, sickle cell disease, CADASIL, & Alcohol consumption \\
coagulopathies) & Physical inactivity \\
& Obstructive sleep apnea \\
& Large artery atherosclerosis: \\
& Extracranial carotid disease \\
& Extracranial vertebrobasilar \\
& disease \\
& Intracranial atherosclerosis \\
& Arterial fibrillation \\
& Aortic atherosclerosis \\
& Patent foramen ovale \\
& Prosthetic heart valves \\
& Valvular heart disease \\
Cardiomyopathy & Acute myocardial infarction \\
& Hypercoagulability \\
Hyperhomocysteinemia \\
Antiphospholipid antibody \\
syndrome \\
\hline
\end{tabular}

Abbreviation: CADASIL, cerebral autosomal dominant arteriopathy with subcortical infarcts and leukoencephalopathy. 


\section{Treatment of the acute phase}

Consistent with animal models of ischemia, the overarching goal of acute ischemic stroke therapy is relieving the arterial occlusion (recanalization) and restoring cerebral blood flow (reperfusion) as soon as possible to reduce tissue injury and improve outcomes. ${ }^{19}$ There is consensus based on strong evidence that in patients presenting within 4.5 hours of symptom onset, intravenous recombinant tissue plasminogen activator (IV rtPA) therapy is beneficial, increasing by $30 \%$ the chances of a good outcome. ${ }^{19}$ However, many patients present with occlusion of a large proximal artery beyond 4.5 hours or have contraindications to systemic thrombolysis (ie, recent major surgery or active bleeding). For these reasons and because proximal artery occlusions are relatively resistant to intravenous thrombolysis, catheter-based or intra-arterial approaches to remove the clot directly and restore blood flow to the brain have been the focus of recent randomized clinical trials. ${ }^{19}$ Based on the results of these multiple randomized clinical trials, intra-arterial therapy using stent retrievers improves recanalization of proximal artery occlusions and clinical outcomes beyond that possible with IV rtPA or supportive care alone. ${ }^{19}$ Moreover, there is strong evidence that endovascular intervention combined with medical management, including IV rtPA for eligible patients, improves the outcomes for appropriately selected patients with acute ischemic stroke in the setting of large vessel occlusion..$^{20,21}$

Apart from treatment of the very acute phase, proper management of the subacute phase of ischemic stroke includes the treatment of neurological complications. These include brain edema, especially in large infarct volume, hemorrhagic transformation of ischemic lesions, and treatment of seizures (prophylactic antiseizure medication is not recommended). ${ }^{22}$ Decompressive surgery should be considered for a spaceoccupying cerebellar infarction and malignant edema of the cerebral hemisphere. ${ }^{22}$ Dysphagia is common after both ischemic and hemorrhagic strokes and is a risk factor for pneumonia. Since screening for dysphagia can reduce the risk of pneumonia, all stroke patients should have a formal swallow screen before taking food, drink, or medication by mouth. ${ }^{22}$ In particular, implementation of a multidisciplinary protocol for the management of swallowing dysfunction, fever, and hyperglycemia, initiated by nurses, delivered better patient outcomes after discharge from stroke units. ${ }^{23}$ Moreover, nutritional support should be implemented to avoid malnutrition, which is associated with increased mortality and poor outcomes..$^{24}$ Finally, physical rehabilitation should be implemented as soon as possible, since it has been associated with better outcome and reduced long-term disability. ${ }^{25}$

\section{Secondary prevention}

On average, the annual risk of future ischemic stroke after an initial ischemic stroke or transient ischemic attack is estimated from $3 \%$ to $4 \%$, but for an individual patient will be affected by particular characteristics of the event and the person, including age, event type, comorbid illness, and adherence to preventive therapy. ${ }^{26}$ Risk factors for secondary prevention of ischemic stroke overlap substantially with that for primary prevention (Table 1). Notably, the annual rate of future stroke has progressively decreased in the past 40-50 years, as the result of important discoveries in prevention science, including antiplatelet therapy and effective strategies for the treatment of hypertension, atrial fibrillation, arterial obstruction, and hyperlipidemia; however, the detailed description of the abovementioned is outside of the aim of this paper. ${ }^{26}$

All these findings together highlight the need for a continuous and careful approach aimed at decreasing the effects of risk factors both at the society level and at the individual level, with the goal of limiting the consequences of acquired disability.

However, apart from the motor, sensory, and language dysfunctions, another frequent and increasingly recognized consequence of stroke is cognitive impairment, ${ }^{27}$ although it has received so far limited attention in the clinical setting. Poststroke cognitive impairment increases survivors' risk of mortality, ${ }^{6}$ disability, ${ }^{28}$ and dependent living ${ }^{28}$ and decreases their quality of life (QoL) ${ }^{29-32}$ with reflections on the chances of institutionalization and caregiver burden. On this evidence, recent clinical practice guidelines and quality improvement programs, with the support of clinical studies, recommended cognitive assessment to be performed for patients with stroke before hospital discharge and also in post-acute settings. ${ }^{33,34}$

\section{Overview of the pathophysiology of cognitive function with age}

Elderly people experience memory loss and cognitive slowing that can interfere with their everyday routines, and cognitive impairment specifically refers to the decline in intellectual capabilities, such as thinking, language, memory, attention, perception, planning, decision making, and problem solving. When cognitive impairment reaches a threshold that hampers daily functioning, the term dementia is used.

According to recent behavioral research, however, cognition in healthy aging is not a regular steady process, and a contrasting pattern of decline and stability across the life span, in relation to different cognitive domains, has been observed. ${ }^{35}$ Indeed, some abilities that are thought to 
be fundamental mechanisms of the cognitive processing architecture, such as encoding new memories of episodes or facts, processing speed, working memory, and executive processes tend to decline linearly across the adult life span. ${ }^{33}$ In contrast, short-term memory and semantic knowledge show little or no decline in performance until very late in life. On the other hand, autobiographical memory and emotional processing remain relatively stable throughout life. ${ }^{35}$ These cognitive changes have been related to structural and functional changes in some specific brain regions, such as the prefrontal cortex, medial temporal lobe regions, and white matter tracts, although much remains unknown and future research is needed in this field. ${ }^{35}$

$\beta$-Amyloid deposition, one of the pathological hallmarks of $\mathrm{AD}$, seems to play a significant role in cognitive dysfunction associated with aging and in cognitively normal elderly individuals is associated with gray matter atrophy (especially in the hippocampus and the posterior cingulate and precuneus regions) and memory impairment. ${ }^{36} \beta$-Amyloid deposition increases progressively across the adult life span, nearly quintuplicating its prevalence from 50 years to 90 years of age ${ }^{37}$ However, recent findings also highlight the role of cerebrovascular disease pathology, besides neurodegenerative abnormalities, in the aging process, and a synergistic role for these two components has been documented. ${ }^{38,39}$ Given these aforementioned vulnerabilities, intrinsically associated with aging, it is not surprising that the major risk factor for the development of cognitive impairment and dementia is increasing age. ${ }^{2}$ However, in the attempt to hinder this process and to promote successful cognitive aging, particular attention has been paid to the potential protective effects of intellectual activity and good health status, and factors, such as education, social class, and social engagement, have been linked to a decreased risk of cognitive decline in later life. ${ }^{40}$ Moreover, over the past $15-20$ years, a growing body of literature has highlighted the significant contribution of stroke and related vascular risk factors (such as hypertension, diabetes, obesity, dyslipidemia, hyperhomocysteinemia, and tobacco smoking) in the development of cognitive decline and dementia, highlighting many potential targets for prevention. ${ }^{3}$

\section{Review on the association of cognitive function with increased risk of stroke with age}

$\mathrm{AD}$ and $\mathrm{VaD}$ are the number 1 and 2 forms of dementia, in terms of prevalence, and together they are responsible for most cases. Historically, these two forms of dementia have

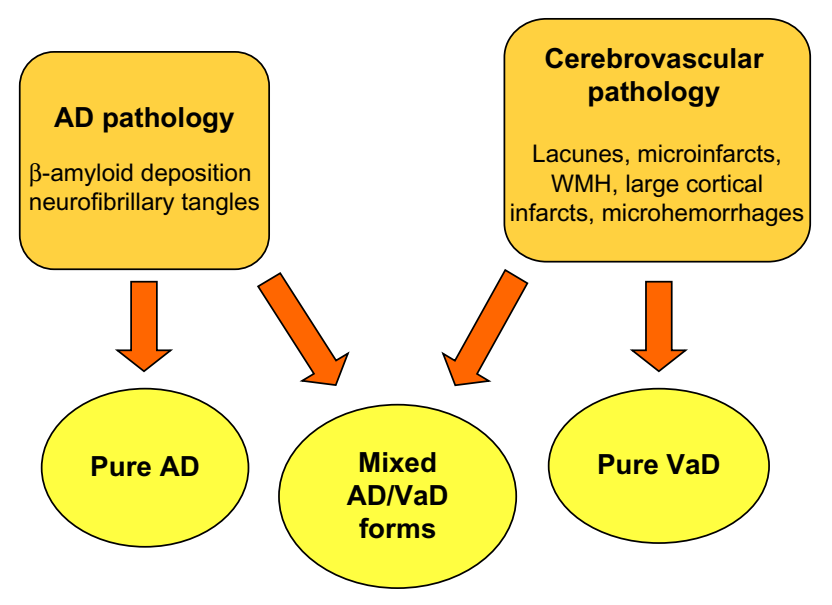

Figure I Interconnected relationship between cerebrovascular disease and Alzheimer's disease (AD) in the genesis of dementia in elderly patients.

Abbreviations: $\mathrm{VaD}$, vascular dementia; $\mathrm{WMH}$, white matter hyperintensities.

been considered as separate entities with distinct clinical and neuropathological changes. However, this assumption has been increasingly criticized by the findings of many studies in the past 15-20 years, leading to the concept of mixed pathological forms (Figure 1) and vascular cognitive impairment (VCI). VCI is a vast syndrome, also including VaD, characterized by the presence of clinical stroke or vascular brain injury and cognitive impairment affecting more than one cognitive domain (Table 2). ${ }^{41}$ There is also a familial form of $\mathrm{VaD}$, known as cerebral autosomal dominant arteriopathy with subcortical infarcts and leukoencephalopathy, caused by mutations in the Notch 3 gene.

From a clinical point of view, AD is often characterized by slowly progressive short-term memory deficits, including recall memory (episodic memory) or factual memory (semantic memory), ${ }^{42}$ followed by the emergence of other cortical deficits, such as aphasia, apraxia, and agnosia. In contrast, VCI is frequently characterized by a stepwise progression of cognitive decline that is closely associated with stroke and focal neurological findings. Moreover, it has

Table 2 The concept of vascular cognitive impairment (VCI)

Vascular cognitive impairment, no dementia (vascular mild cognitive impairment)

Poststroke dementia

Vascular dementia

Multi-infarct dementia

Strategic infarct dementia (eg, thalamus and hippocampus)

Cerebral small vessel disease (subcortical ischemic vascular dementia

or Binswanger's disease)

Hypoperfusion dementia

Hemorrhagic dementia

Alzheimer's disease with cerebrovascular disease (mixed dementia) 
been associated mainly with subcortical disturbances causing frontal executive dysfunction demonstrated by the lack of performance in planning and execution of an activity, followed by slowing of cognition and changes in personality. ${ }^{41}$ In practice, however, many memory tests, such as those depending on free recall, involve executive abilities, and the differentiation of $\mathrm{VCI}$ from pure $\mathrm{AD}$ remains challenging, exhibiting low specificity when using a purely clinical approach.

Even from a neuropathological point of view, differentiation between $\mathrm{AD}$ and $\mathrm{VCI}$ is not straightforward (Figure 1). Pure AD forms should be characterized by $\beta$-amyloid deposition in brain parenchyma and blood vessels and by neurofibrillary tangles. In contrast, pathological findings in $\mathrm{VaD}$ should include discrete infarction, especially involving cortical regions, hemorrhages, and white matter lesions. ${ }^{41}$ Many autoptic studies, however, have demonstrated an overlap of histopathological findings between $\mathrm{AD}$ and VCI and the prevalence of both conditions in patients undergoing autopsy ranges from $25 \%$ to $50 \% .^{43,44}$ Moreover, neuropathological studies have shown that cerebrovascular disease (stroke, silent infarction, small vessel disease, microinfarction, and cerebral amyloid angiopathy) is responsible for the majority of cases of older onset dementia. ${ }^{45,46}$ The attributable risk of vascular lesions for all-cause dementia is also higher than that for cortical $\beta$-amyloid plaques and neurofibrillary tangles combined, ${ }^{47}$ even if the burden of $\beta$-amyloid deposition plays a significant role. ${ }^{48}$

Many epidemiological studies also lend support to the concept that stroke and dementia are interrelated. ${ }^{49}$ They share similar risk factors, and the risk of one condition is increased in the presence of the other. ${ }^{50}$ Dementia prevalence among people with a history of stroke is similar to that seen in subjects 10 years older without a history of stroke. ${ }^{51}$ Studies that investigated patients suffering from stroke indicated that $\sim 10 \%$ have dementia prior to first stroke and up to $10 \%$ may have new dementia in the first year after stroke occurrence. ${ }^{49}$ When considering patients with recurrent stroke, these rates increase over $30 \%$, regardless of the number and severity of vascular risk factors they had been exposed to before the stroke. ${ }^{49,52}$ After the immediate high-risk poststroke period, rates of new incident dementia decrease but remain elevated at around four times the background risk..$^{34,49}$ Risk factors associated with prestroke and poststroke dementia are broadly similar, but age, medial temporal lobe atrophy, female sex, and family history are more strongly associated with prestroke dementia, suggesting a greater role for a preexisting degenerative pathology. ${ }^{49}$ In contrast, poststroke dementia is associated with factors indicating a reduced cognitive reserve (prestroke cognitive decline, premorbid disability, low education, white matter disease, and atrophy). It is also strongly associated with stroke factors (lesion size, multiple lesions, and stroke recurrence) and complications of stroke (delirium, seizures, hypotension, systemic illness, and incontinence). ${ }^{49}$ All these findings underscore the likely impact of optimal acute stroke care and secondary prevention in reducing the burden of dementia. Intriguingly, a reverse association is also true, and cognitive impairment has been strongly and independently associated with an increased risk of stroke. ${ }^{53}$ Since small vessel disease plays a relevant role in stroke pathophysiology and is a leading cause of cognitive decline and functional loss in elderly patients, small vessel disease should also be a main target for preventive and treatment strategies aimed at VCI and stroke. ${ }^{54}$

\section{Current treatment and therapies}

The mechanisms linking stroke to cognitive impairment and dementia are still unclear, and two partially conflicting hypotheses have been proposed..$^{55}$ The first hypothesis emphasizes the central role of stroke itself in the development of cognitive impairment and gains support for the strong association of poststroke dementia with multiple strokes and the well-defined prognostic value of many stroke characteristics, such as hemorrhagic stroke, left hemisphere stroke, dysphasia, stroke severity, and infarct volume. ${ }^{55}$ In this event, the best preventive strategy in reducing the burden of dementia should be oriented toward optimum acute stroke care and secondary prevention of stroke recurrence, as outlined in the first sections of this review.

The alternative hypothesis highlights the role of vascular risk factors (Figure 2). Accordingly, poststroke dementia should be considered as the consequence of stroke-related aggravation of preexisting vascular risk factors, white matter changes, and associated degenerative pathology, including

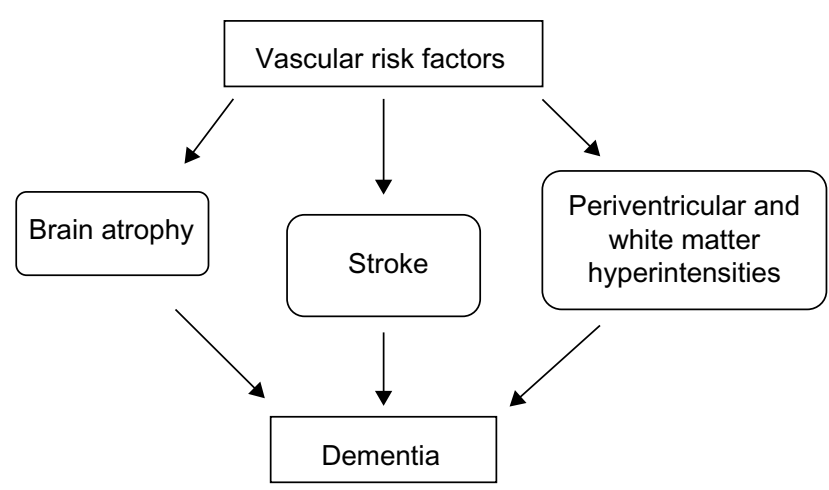

Figure 2 The potential role of vascular risk factors in the development of dementia in elderly patients. 
$\beta$-amyloid plaques deposition, rather than stroke alone. ${ }^{56,57}$ As a result, systematic treatment of vascular risk factors could represent the best available preventive strategy for both stroke and dementia in aging people. ${ }^{58}$ In this respect, hypertension is the vascular risk factor with more substantial evidence from observational studies and clinical trials, underlying a central role in the development of cognitive impairment and dementia.

The role of hypertension on the cognitive decline has been investigated in many studies, and high blood pressure, especially in midlife, has been shown to predict poor cognitive outcomes many years later, although some studies have reported a J- or U-shaped relation. ${ }^{59,60}$ High blood pressure has also been associated with impaired results on tests of executive function ${ }^{61}$ and with white matter hyperintensities (WMHs) and subclinical infarcts, pathogenically linked to VCI. ${ }^{62}$ Although the mechanisms underlying the disruptive effects of hypertension on cognition in elderly people are not entirely understood, hypertension has been associated with the development of the pathological features of $\mathrm{AD}$, including neurofibrillary tangles and $\beta$-amyloid plaques, ${ }^{63}$ as well as to cerebrovascular disease pathology and WMHs in the brain. ${ }^{64}$ Arterial stiffness appears to play a significant role in the relationship between hypertension and its consequences. ${ }^{65}$ There is also increasing evidence, from clinical trials, suggesting that treating hypertension to prevent heart disease and stroke decreases the risk of cognitive impairment, with positive effects observed with calcium channel blockers, such as lercanidipine and nitrendipine, the combination perindopril-indapamide, and telmisartan. ${ }^{9}$ Interestingly, antihypertensive medication could decrease the risk of not only VaD but also AD., ${ }^{9,10}$

Besides hypertension, other vascular and stroke risk factors such as diabetes mellitus, atrial fibrillation, dyslipidemia, smoking, obesity, and alcohol consumption could also be the therapy target of stroke-related cognitive impairment. ${ }^{3}$ Moreover, there is evidence that maintaining ideal cardiovascular health in young adulthood to middle age could be related to better performance on cognition in later life. ${ }^{66}$ This finding reinforces the concept that the timing of interventions targeting vascular risk factors could also play a relevant role because the association with dementia appears to be stronger for vascular factors when measured in midlife rather than in old age, which suggests that midlife may be a critical period. ${ }^{60}$ Notably, there is no evidence supporting beneficial effects of antiplatelet agents on cognition. ${ }^{60}$

However, it is not just the classical vascular risk factors that might contribute to both stroke and AD risk. Indeed, the presence of $A P O E \varepsilon 4$ is a well-established genetic risk factor for $\mathrm{AD}$, but it also increases the risk of vascular disease, and accelerates atherogenesis, as a result of impaired cholesterol transport and metabolism. APOE genotype is associated with progression of WMHs load, as well as being related to poststroke cognitive decline. ${ }^{67}$

Although there is no specific drug approved for the treatment of cognitive impairment from the vascular origin, many pharmacological approaches have been tested for stroke-related cognitive impairment. Cholinesterase inhibitors, donepezil, galantamine, and rivastigmine, have been approved to treat the cholinergic compromise in $\mathrm{AD}$ and have also shown consistent, although modest cognitive improvements in patients with VCI ${ }^{60}$ However, functional and global benefits were lacking and difficult to assess in these patients, because of stroke-related disability, ${ }^{60}$ and concerns have been raised about the clinical significance of these results. ${ }^{68}$ Nevertheless, donepezil studies are those that provided the best available evidence for a beneficial effect for pure $\mathrm{VaD}$, and galantamine for mixed $\mathrm{AD} / \mathrm{VaD}$ states, whereas a benefit of rivastigmine is still not proven. ${ }^{60}$ Two studies with memantine, an $N$-methyl D-aspartate antagonist approved for the treatment of moderate-to-severe AD, likewise showed some cognitive improvements without global or functional benefit in VCI. ${ }^{60}$ No head-to-head trials, however, have been conducted so far, so it is unclear whether there are any differential benefits within or between these drug classes. ${ }^{60}$

Other treatments, such as citicoline, nimodipine, Ginkgo biloba, and long-chain omega-3 polyunsaturated fatty acids (O-3-FAs), have received some attention as potential useful treatments for patients with poststroke cognitive impairment.

Citicoline, an essential intermediate in the biosynthetic pathway of structural phospholipids in cell membranes, has shown neuroprotective activity in preclinical models of brain ischemia and trauma. ${ }^{69}$ Two clinical trials showed some improvement in cognition of patients with VCI (500 mg twice a day), after a follow-up of 9-12 months. $^{70,71}$ As a result, citicoline has been suggested as a promising alternative to improve stroke recovery and to prevent VCI. ${ }^{69}$

Calcium channel blockade attenuates the $\beta$-amyloidinduced neuronal decline in vitro and has shown neuroprotective activity in animal models. ${ }^{72}$ Hence, several calcium channel blockers have been tested in clinical trials of dementia, but the outcome is heterogeneous. Nimodipine, an isopropyl calcium channel blocker that readily crosses the blood-brain barrier, showed the most consistent, albeit small, positive results on cognitive decline (Nimodipine dosage: $90 \mathrm{mg} / \mathrm{d}$ ). Interestingly, a direct protecting effect on neurons was inferred, whereas blood pressure reduction did not 
seem to play a significant role. However, since no effects on scales assessing the activities of daily living were observed, and considering the short-term benefits demonstrated in the clinical trials, the use of nimodipine has not been justified as a long-term antidementia drug. ${ }^{72}$

G. biloba extract, a traditional natural herbal product, has also been tested in patients with dementia and VCI. The results have collectively shown a small but positive effect on cognitive functions, neuropsychiatric symptoms, and functional abilities for patients treated with the extract $(240 \mathrm{mg}$ once-daily preparation) compared to placebo. ${ }^{73-75}$

O-3-FAs have antioxidant and anti-inflammatory properties and are major components of membrane phospholipids in the brain, playing a critical role in neuronal function. Hence, the role of supplementation of O-3-FAs on cognition and the development of dementia has been the target of some clinical trials, but conflicting results were reported. ${ }^{76-78}$ However, O-3-FAs may help to reduce blood pressure, ${ }^{79}$ and have shown beneficial effects on stroke, especially in women. ${ }^{80}$

Apart from pharmacological treatment, promising hope comes from some nonpharmaceutical approaches, such as diet, cognitive training (CT), cognitive rehabilitation, and physical function.

There is some evidence that a Mediterranean diet can reduce cognitive decline,${ }^{81}$ and better adherence to a Mediterranean-type dietary pattern has been associated with less cognitive decline and less brain atrophy in a community with older subjects and less brain atrophy, with an effect similar to 5 years of aging. ${ }^{82,83}$ Moreover, a recently published randomized clinical trial in cognitively healthy elderly volunteers has also shown that a Mediterranean diet supplemented with olive oil or nuts was associated with improved cognitive function, including memory, and executive functions compared with a control diet. ${ }^{84}$

CT involves repeated practice of standardized tasks targeting a particular cognitive function, and cognitive stimulation implies a range of social and cognitive activities to stimulate multiple cognitive domains. Although CT and cognitive stimulation offer a potential approach for dementia prevention and maintenance of cognitive function in older adults, cognitive rehabilitation so far has not proven to be effective. ${ }^{85}$ However, there are few randomized controlled trials, and there are methodological limitations in existing studies in these areas.

Physical activity has been shown to increase brain neurotrophins, improve cerebrovascular functioning and brain perfusion, reduce response to stress, and increase brain plasticity through synaptogenesis and neurogenesis. ${ }^{86}$ There is good evidence to recommend an individualized exercise program for patients with mild-to-moderate dementia, and long-term regular physical activity, including vigorous activity and walking, has been associated with higher levels of cognitive function, less cognitive decline, and less VCI. ${ }^{60}$ For those able to engage in exercise, the American Heart Association recommends 30 minutes of exercise of moderate intensity on most days. For those with a disability, a supervised therapeutic regimen may be implemented. ${ }^{60}$ Notably, a recent meta-analysis confirmed that physical activity interventions positively influence cognitive function in patients with dementia. ${ }^{87}$ This beneficial effect was independent of the clinical diagnosis (AD or other dementias) and the frequency of the intervention and was driven by interventions that included aerobic exercise. ${ }^{87}$

Finally, interesting findings have recently emerged for multifaceted approaches. The Healthy Brain Ageing Cognitive Training (HBA-CT) program for older adults at risk of dementia comprised group-based psychoeducation about cognitive strategies and modifiable lifestyle factors about healthy brain aging, and computerized CT, twice-weekly for 7 weeks. In comparison to the treatment as usual control arm, the HBA-CT program was associated with improvements in cognitive, mood, and sleep functions, therefore offering promise as a secondary prevention strategy ${ }^{88}$ In the Finnish Geriatric Intervention Study to Prevent Cognitive Impairment and Disability (FINGER) trial, a multidomain intervention (including diet, exercise, CT, and vascular risk monitoring) was associated with improvement or maintenance of cognitive functioning in at-risk elderly people from the general population, aged $60-77$ years. ${ }^{89}$

\section{Implications for enhanced patient care such as QoL}

Many facets of dementia care do not involve therapies directed at disease modification or at improving physical function, and, in the context of a multidimensional approach, QoL has become viewed as the endpoint most relevant to the individual. ${ }^{90}$ QoL can be defined as a multidimensional concept that incorporates physical, psychological, and social domains of health and well-being, nested in the context of individual's values, expectations, and cultural beliefs..$^{91,92}$ It has been shown that handicap, physical impairment, and disability after stroke were all independent predictors of health-related QoL, as well as dementia and depression. ${ }^{29}$ Moreover, several cognitive tasks - mostly in the attention domain - administered at 2 months poststroke were predictive of QoL at 10 months. ${ }^{30}$ Furthermore, cognitive impairment, in the first month poststroke, was shown as an independent predictor of low QoL at 6-10 months. ${ }^{31}$ Interestingly, QoL 
was found significantly reduced not only in patients with poststroke dementia but also in patients with vascular mild cognitive impairment. ${ }^{93}$ Finally, Cumming et al showed that cognitive impairment at 3 months poststroke, and particularly poorer attention and visuospatial ability, was associated with lower QoL at 12 months poststroke, even when important covariates (age, stroke severity, and depression) were taken into account. ${ }^{32}$ Taken together, the results of these studies support the idea that cognitive function plays a relevant role in determining QoL after stroke. As such, there is a need for further research to identify strategies that can improve cognition in stroke survivors and to investigate the potential reflections on their QoL.

Another important aspect to take into account is caregivers' support since there is evidence that burden of care and physical strain, associated with the caregiving assistance, might reflect in reduced QoL of caregivers as well as patients. ${ }^{94}$ Cognitive impairment after stroke has been shown to add significantly to this burden. ${ }^{95,96}$ Moreover, social networks and patient and family support have been associated with cognitive functioning in elderly populations. ${ }^{60}$ Then, it is of utmost importance to work with the primary caregiver on an ongoing basis, assessing health and psychological status, including distress, anxiety, depression, and sleeprelated complaints. ${ }^{97,98}$ If any are present and compelling, consideration should be given to referring the patient to a specialized dementia service that can offer treatment and support. Multicomponent interventions providing education, counseling, support, and respite to caregivers seem the most promising and can also significantly delay the need for institutional care for patients with dementia. ${ }^{60,99}$ Caregivers should also be informed of the local home care program since it may be able to provide information on available community resources, provide anticipatory guidance, assist with personal care when the need arises, and look at the need for respite services. ${ }^{60,99}$ Finally, it should be outlined that cognitive and physical impairment after stroke could lead to the loss of capacity to make financial and medical decisions with significant reflections on caregiving activities, and the provision of palliative care in the case of progressive disease should also be considered. ${ }^{60}$

\section{Conclusion}

The relationship between cognitive impairment and stroke is complex, and many aspects are still obscure (Figure 3 ). However, numerous studies in the past 20-30 years have outlined that the prevalence of cognitive impairment after stroke is high, especially after stroke recurrence, and demographic factors such as age, education, and occupation, as well as hypertension, diet, and physical activity, all play a significant role.

Most recent findings support the notion that cognitive impairment in elderly people, and in the context of a detrimental genetic milieu, is likely the result of a synergistic interplay between neurodegenerative changes that progressively occur in many cerebral regions. This process has to start 20-30 years before the onset of clinical dementia and cerebrovascular disease, causing neuroanatomical lesions on strategic areas of the brain. Further research is needed to better elucidate this relationship.

General strategies for managing these patients have been developed, and there is increasing attention toward the systematic treatment of vascular risk factors, as a preventive

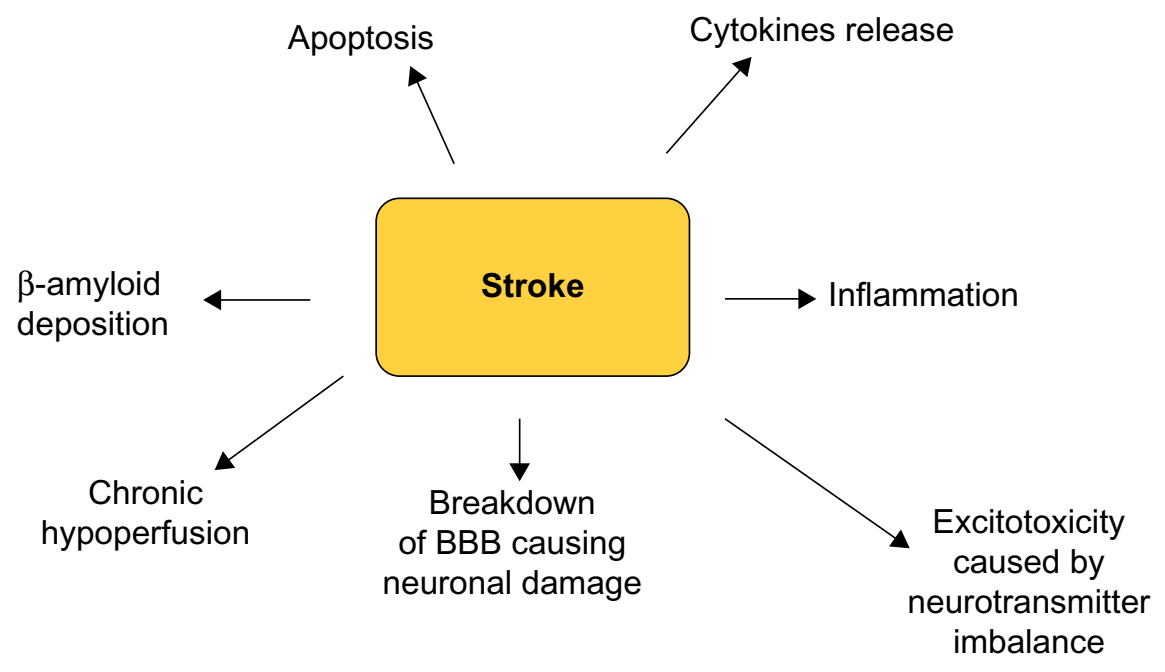

Figure 3 Potential mechanisms underlying the association between stroke and dementia. Abbreviation: BBB, blood-brain barrier. 
Table 3 Current knowledge gaps and future directions in stroke-dementia interaction

\begin{tabular}{|c|c|c|}
\hline Area of uncertainty & Knowledge gap & Future direction \\
\hline $\begin{array}{l}\text { Insights into pathogenetic } \\
\text { mechanisms }\end{array}$ & $\begin{array}{l}\text { The mechanisms linking stroke and cerebrovascular } \\
\text { disease to cognitive impairment and dementia are } \\
\text { still partially obscure }\end{array}$ & $\begin{array}{l}\text { Basic science studies, clinical surveys, as } \\
\text { well as neuroimaging and genetic studies are } \\
\text { awaited }\end{array}$ \\
\hline $\begin{array}{l}\text { Efficacy and feasibility of } \\
\text { preventive strategies }\end{array}$ & $\begin{array}{l}\text { Although stroke and dementia prevention and } \\
\text { treatment are a worldwide priority, we still do not } \\
\text { know how many cases can be effectively prevented, } \\
\text { and which are the most effective interventions (changes } \\
\text { in lifestyle and health behavior, pharmacological } \\
\text { management of cardiovascular risk factors, } \\
\text { neuroprotective drugs, etc) }\end{array}$ & $\begin{array}{l}\text { Epidemiological studies and clinical trials are } \\
\text { warranted }\end{array}$ \\
\hline $\begin{array}{l}\text { Effective treatments and } \\
\text { interventions }\end{array}$ & $\begin{array}{l}\text { At present, there is no specific pharmacological } \\
\text { treatment approved for the treatment of } \\
\text { vascular cognitive impairment, and efficacy of } \\
\text { nonpharmacological approaches is still under study }\end{array}$ & $\begin{array}{l}\text { Future clinical trials are expected to assess } \\
\text { the efficacy of both new pharmacological and } \\
\text { nonpharmacological treatments, as well as the } \\
\text { effects of multidomain approaches }\end{array}$ \\
\hline $\begin{array}{l}\text { Implementation of enhanced } \\
\text { patient care }\end{array}$ & $\begin{array}{l}\text { Stroke and dementia are major causes of mortality } \\
\text { and disability. Consequent reflections on physical, } \\
\text { psychological, and social domains of health and } \\
\text { well-being of both patient and caregiver are still } \\
\text { insufficiently investigated in clinical practice }\end{array}$ & $\begin{array}{l}\text { Targeted interventions aimed at quality of life } \\
\text { and caregiver support should be stimulated }\end{array}$ \\
\hline
\end{tabular}

strategy, especially antihypertensive medications such as calcium channel blockers and renin-angiotensin system blockers. Moreover, stroke-related cognitive impairment might benefit from antidementia treatments and also from some nonpharmaceutical approaches, such as diet, cognitive rehabilitation, and physical activity. However, further studies are still needed to better define the efficacy of various therapy strategies. Finally, increasing efforts should be directed to implement a multidimensional approach, with particular attention to the QoL issues and caregivers support (Table 3).

\section{Disclosure}

The authors report no conflicts of interest in this work.

\section{References}

1. Prince M, Bryce R, Albanese E, Wimo A, Ribeiro W, Ferri CP. The global prevalence of dementia: a systematic review and metaanalysis. Alzheimers Dement. 2013;9:63-75.e2.

2. Wallin K, Bostrom G, Kivipelto M, Gustafson Y. Risk factors for incident dementia in the very old. Int Psychogeriatr. 2013;25:1135-1143.

3. Sahathevan R, Brodtmann A, Donnan GA. Dementia, stroke, and vascular risk factors; a review. Int J Stroke. 2012;7(1):61-73.

4. Feigin VL, Forouzanfar MH, Krishnamurthi R, et al; Global Burden of Diseases, Injuries, and Risk Factors Study 2010 (GBD 2010) and the GBD Stroke Experts Group. Global and regional burden of stroke during 1990-2010: findings from the Global Burden of Disease Study 2010. Lancet. 2014;383(9913):245-254.

5. Franchi C, Nobili A, Mari D, et al; REPOSI Investigators. Risk factors for hospital readmission of elderly patients. Eur J Intern Med. 2013; 24(1):45-51.

6. Tatemichi TK, Paik M, Bagiella E, Desmond DW, Pirro M, Hanzawa LK. Dementia after stroke is a predictor of long-term survival. Stroke. 1994;25(10):1915-1919.
7. Marengoni A, Nobili A, Romano V, et al; SIMI Investigators. Adverse clinical events and mortality during hospitalization and 3 months after discharge in cognitively impaired elderly patients. J Gerontol A Biol Sci Med Sci. 2013;68(4):419-425.

8. Marengoni A, Corrao S, Nobili A, et al; SIMI Investigators. In-hospital death according to dementia diagnosis in acutely ill elderly patients: the REPOSI study. Int J Geriatr Psychiatry. 2011;26(9):930-936.

9. Rouch L, Cestac P, Hanon O, et al. Antihypertensive drugs, prevention of cognitive decline and dementia: a systematic review of observational studies, randomized controlled trials and meta-analyses, with discussion of potential mechanisms. CNS Drugs. 2015;29(2):113-130.

10. Wharton W, Goldstein FC, Zhao L, Steenland K, Levey AI, Hajjar I. Modulation of renin-angiotensin system may slow conversion from mild cognitive impairment to Alzheimer's disease. J Am Geriatr Soc. 2015;63(9):1749-1756.

11. Brookmeyer R, Johnson E, Ziegler-Graham K, Arrighi HM. Forecasting the global burden of Alzheimer's disease. Alzheimers Dement. 2007; 3:186-191.

12. Seshadri S, Wolf PA. Lifetime risk of stroke and dementia: current concepts, and estimates from the Framingham Study. Lancet Neurol. 2007;6(12):1106-1114.

13. Rocca WA, Petersen RC, Knopman DS, et al. Trends in the incidence and prevalence of Alzheimer's disease, dementia, and cognitive impairment in the United States. Alzheimers Dement. 2011;7:80-93.

14. Schrijvers EM, Verhaaren BF, Koudstaal PJ, Hofman A, Ikram MA, Breteler MM. Is dementia incidence declining?: trends in dementia incidence since 1990 in the Rotterdam Study. Neurology. 2012; 78(19):1456-1463.

15. Christensen K, Thinggaard M, Oksuzyan A, et al. Physical and cognitive functioning of people older than 90 years: a comparison of two Danish cohorts born 10 years apart. Lancet. 2013;382(9903):1507-1513.

16. Wu YT, Fratiglioni L, Matthews FE, et al. Dementia in western Europe: epidemiological evidence and implications for policy making. Lancet Neurol. 2016;15(1):116-124.

17. Meschia JF, Bushnell C, Boden-Albala B, et al; American Heart Association Stroke Council; Council on Cardiovascular and Stroke Nursing; Council on Clinical Cardiology; Council on Functional Genomics and Translational Biology; Council on Hypertension. Guidelines for the primary prevention of stroke: a statement for healthcare professionals from the American Heart Association/American Stroke Association. Stroke. 2014;45(12):3754-3832. 
18. Zanchetti A, Thomopoulos C, Parati G. Randomized controlled trials of blood pressure lowering in hypertension: a critical reappraisal. Circ Res. 2015;116(6):1058-1073.

19. Prabhakaran S, Ruff I, Bernstein RA. Acute stroke intervention: a systematic review. JAMA. 2015;313(14):1451-1462.

20. Chen CJ, Ding D, Starke RM, et al. Endovascular vs medical management of acute ischemic stroke. Neurology. 2015;85(22):1980-1990.

21. Powers WJ, Derdeyn CP, Biller J, et al; American Heart Association Stroke Council. 2015 American Heart Association/American Stroke Association focused update of the 2013 guidelines for the early management of patients with acute ischemic stroke regarding endovascular treatment: a guideline for healthcare professionals from the American Heart Association/American Stroke Association. Stroke. 2015;46(10):3020-3035.

22. Jauch EC, Saver JL, Adams HP Jr, et al; American Heart Association Stroke Council; Council on Cardiovascular Nursing; Council on Peripheral Vascular Disease; Council on Clinical Cardiology. Guidelines for the early management of patients with acute ischemic stroke: a guideline for healthcare professionals from the American Heart Association/ American Stroke Association. Stroke. 2013;44(3):870-947.

23. Middleton S, McElduff P, Ward J, et al; QASC Trialists Group. Implementation of evidence-based treatment protocols to manage fever, hyperglycaemia, and swallowing dysfunction in acute stroke (QASC): a cluster randomised controlled trial. Lancet. 2011;378(9804):1699-1706.

24. Gomes F, Hookway C, Weekes CE; Royal College of Physicians Intercollegiate Stroke Working Party. Royal college of physicians intercollegiate stroke working party evidence-based guidelines for the nutritional support of patients who have had a stroke. J Hum Nutr Diet. 2014;27(2):107-121.

25. Pollock A, Baer G, Campbell P, et al. Physical rehabilitation approaches for the recovery of function and mobility following stroke. Cochrane Database Syst Rev. 2014;4:CD001920.

26. Kernan WN, Ovbiagele B, Black HR, et al; American Heart Association Stroke Council, Council on Cardiovascular and Stroke Nursing, Council on Clinical Cardiology, and Council on Peripheral Vascular Disease. Guidelines for the prevention of stroke in patients with stroke and transient ischemic attack: a guideline for healthcare professionals from the American Heart Association/American Stroke Association. Stroke. 2014;45(7):2160-2236.

27. Ukraintseva S, Sloan F, Arbeev K, Yashin A. Increasing rates of dementia at time of declining mortality from stroke. Stroke. 2006; 37(5):1155-1159.

28. Patel MD, Coshall C, Rudd AG, Wolfe CD. Cognitive impairment after stroke: clinical determinants and its associations with long-term stroke outcomes. J Am Geriatr Soc. 2002;50(4):700-706.

29. Sturm JW, Donnan GA, Dewey HM, et al. Quality of life after stroke: the North East Melbourne Stroke Incidence Study (NEMESIS). Stroke. 2004;35(10):2340-2345.

30. Hochstenbach JB, Anderson PG, van Limbeek J, Mulder TT. Is there a relation between neuropsychologic variables and quality of life after stroke? Arch Phys Med Rehabil. 2001;82(10):1360-1366.

31. Nys GM, van Zandvoort MJ, van der Worp HB, et al. Early cognitive impairment predicts long-term depressive symptoms and quality of life after stroke. J Neurol Sci. 2006;247(2):149-156.

32. Cumming TB, Brodtmann A, Darby D, Bernhardt J. The importance of cognition to quality of life after stroke. J Psychosom Res. 2014;77(5): 374-379.

33. Miller EL, Murray L, Richards L, et al; American Heart Association Council on Cardiovascular Nursing and the Stroke Council. Comprehensive overview of nursing and interdisciplinary rehabilitation care of the stroke patient: a scientific statement from the American Heart Association. Stroke. 2010;41(10):2402-2448.

34. Levine DA, Galecki AT, Langa KM, et al. Trajectory of cognitive decline after incident stroke. JAMA. 2015;314(1):41-51.

35. Hedden T, Gabrieli JD. Insights into the ageing mind: a view from cognitive neuroscience. Nat Rev Neurosci. 2004;5(2):87-96.
36. Doré V, Villemagne VL, Bourgeat $\mathrm{P}$, et al. Cross-sectional and longitudinal analysis of the relationship between $\mathrm{A} \beta$ deposition, cortical thickness, and memory in cognitively unimpaired individuals and in Alzheimer disease. JAMA Neurol. 2013;70(7):903-911.

37. Jansen WJ, Ossenkoppele R, Knol DL, et al. Prevalence of cerebral amyloid pathology in persons without dementia: a meta-analysis. JAMA. 2015;313(19):1924-1938.

38. Wirth M, Villeneuve S, Haase CM, et al. Associations between Alzheimer disease biomarkers, neurodegeneration, and cognition in cognitively normal older people. JAMA Neurol. 2013;70(12):1512-1519.

39. Lee MJ, Seo SW, Na DL, et al. Synergistic effects of ischemia and $\beta$-amyloid burden on cognitive decline in patients with subcortical vascular mild cognitive impairment. JAMA Psychiatry. 2014;71(4): 412-422.

40. Matthews F, Marioni R, Brayne C; Medical Research Council Cognitive Function and Ageing Study. Examining the influence of gender, education, social class and birth cohort on MMSE tracking over time: a population based prospective cohort study. BMC Geriatr. $2012 ; 12: 45$.

41. O’Brien JT, Erkinjuntti T, Reisberg B, et al. Vascular cognitive impairment. Lancet Neurol. 2003;2(2):89-98.

42. Gold CA, Budson AE. Memory loss in Alzheimer's disease: implications for development of therapeutics. Expert Rev Neurother. 2008;8:1879-1891.

43. Riley KP, Snowdon DA, Markesbery WR. Alzheimer's neurofibrillary pathology and the spectrum of cognitive function: findings from the Nun Study. Ann Neurol. 2002;51(5):567-577.

44. Jellinger KA. The enigma of vascular cognitive disorder and vascular dementia. Acta Neuropathol. 2007;113(4):349-388.

45. Schneider JA, Arvanitakis Z, Bang W, Bennett DA. Mixed brain pathologies account for most dementia cases in community-dwelling older persons. Neurology. 2007;69(24):2197-2204.

46. Sonnen JA, Larson EB, Crane PK, et al. Pathological correlates of dementia in a longitudinal, population-based sample of aging. Ann Neurol. 2007;62(4):406-413.

47. Matthews FE, Brayne C, Lowe J, McKeith I, Wharton SB, Ince P. Epidemiological pathology of dementia: attributable-risks at death in the Medical Research Council Cognitive Function and Ageing Study. PLoS Med. 2009;6:e1000180.

48. Ye BS, Seo SW, Kim JH, et al. Effects of amyloid and vascular markers on cognitive decline in subcortical vascular dementia. Neurology. 2015;85(19):1687-1693.

49. Pendlebury ST. Dementia in patients hospitalized with stroke: rates, time course, and clinico-pathologic factors. Int $J$ Stroke. 2012;7(7):570-581.

50. Rostamian S, Mahinrad S, Stijnen T, Sabayan B, de Craen AJ. Cognitive impairment and risk of stroke: a systematic review and meta-analysis of prospective cohort studies. Stroke. 2014;45(5):1342-1348.

51. De Ronchi D, Palmer K, Pioggiosi P, et al. The combined effect of age, education, and stroke on dementia and cognitive impairment no dementia in the elderly. Dement Geriatr Cogn Disord. 2007;24(4): 266-273.

52. Pendlebury ST, Rothwell PM. Prevalence, incidence, and factors associated with pre-stroke and post-stroke dementia: a systematic review and meta-analysis. Lancet Neurol. 2009;8(11):1006-1018.

53. Sabayan B, Gussekloo J, de Ruijter W, Westendorp RG, de Craen AJ. Framingham stroke risk score and cognitive impairment for predicting first-time stroke in the oldest old. Stroke. 2013;44(7):1866-1871.

54. Pantoni L. Cerebral small vessel disease: from pathogenesis and clinical characteristics to therapeutic challenges. Lancet Neurol. 2010;9(7):689-701.

55. Hennerici MG. What are the mechanisms for post-stroke dementia? Lancet Neurol. 2009;8(11):973-975.

56. Henon H, Pasquier F, Durieu I, et al. Pre-existing dementia in stroke patients: baseline frequency, associated factors and outcome. Stroke. 1997;28(12):2429-2436. 
57. Pantoni L, Basile AM, Pracucci G, et al. Impact of age-related cerebral white matter changes on the transition to disability. The LADIS (leukoaraiosis and disability in the elderly) study: rationale, design and methodology. Neuroepidemiology. 2005;24(1-2):51-62.

58. European Stroke Organisation (ESO) Executive Committee. Guidelines for the management of ischaemic stroke and transient ischaemic attack 2008. Cerebrovasc Dis. 2008;25(5):457-507.

59. Sharp SI, Aarsland D, Day S, Sønnesyn H; Alzheimer's Society Vascular Dementia Systematic Review Group, Ballard C. Hypertension is a potential risk factor for vascular dementia: systematic review. Int J Geriatr Psychiatry. 2011;26(7):661-669.

60. Gorelick PB, Scuteri A, Black SE, et al; American Heart Association Stroke Council, Council on Epidemiology and Prevention, Council on Cardiovascular Nursing, Council on Cardiovascular Radiology and Intervention, and Council on Cardiovascular Surgery and Anesthesia. Vascular contributions to cognitive impairment and dementia: a statement for healthcare professionals from the American Heart Association/ American Stroke Association. Stroke. 2011;42(9):2672-2713.

61. Kramer JH, Reed BR, Mungas D, Weiner MW, Chui HC. Executive dysfunction in subcortical ischaemic vascular disease. $J$ Neurol Neurosurg Psychiatry. 2002;72(2):217-220.

62. Longstreth WT Jr, Bernick C, Manolio TA, Bryan N, Jungreis CA, Price TR. Lacunar infarcts defined by magnetic resonance imaging of 3660 elderly people: the Cardiovascular Health Study. Arch Neurol. 1998;55(9):1217-1225.

63. Sparks DL, Scheff SW, Liu H, Landers TM, Coyne CM, Hunsaker JC 3rd. Increased incidence of neurofibrillary tangles (NFT) in non-demented individuals with hypertension. J Neurol Sci. 1995;131(2):162-169.

64. Yang C, DeVisser A, Martinez JA, et al. Differential impact of diabetes and hypertension in the brain: adverse effects in white matter. Neurobiol Dis. 2011;42(3):446-458.

65. Hughes TM, Kuller LH, Barinas-Mitchell EJ, et al. Arterial stiffness and $\beta$-amyloid progression in nondemented elderly adults. JAMA Neurol. 2014;71(5):562-568.

66. Reis JP, Loria CM, Launer LJ, et al. Cardiovascular health through young adulthood and cognitive functioning in midlife. Ann Neurol. 2013;73(2):170-179.

67. Cumming TB, Brodtmann A. Can stroke cause neurodegenerative dementia? Int J Stroke. 2011;6(5):416-424.

68. Kavirajan H, Schneider LS. Efficacy and adverse effects of cholinesterase inhibitors and memantine in vascular dementia: a meta-analysis of randomised controlled trials. Lancet Neurol. 2007;6(9):782-792.

69. Gareri P, Castagna A, Cotroneo AM, Putignano S, De Sarro G, Bruni AC The role of citicoline in cognitive impairment: pharmacological characteristics, possible advantages, and doubts for an old drug with new perspectives. Clin Interv Aging. 2015;10:1421-1429.

70. Cotroneo AM, Castagna A, Putignano S, et al. Effectiveness and safety of citicoline in mild vascular cognitive impairment: the IDEALE study. Clin Interv Aging. 2013;8:131-137.

71. Alvarez-Sabín J, Ortega G, Jacas C, et al. Long-term treatment with citicoline may improve poststroke vascular cognitive impairment. Cerebrovasc Dis. 2013;35(2):146-154.

72. Nimmrich V, Eckert A. Calcium channel blockers and dementia. $\mathrm{Br} J$ Pharmacol. 2013;169(6):1203-1210.

73. Wang BS, Wang H, Song YY, et al. Effectiveness of standardized ginkgo biloba extract on cognitive symptoms of dementia with a six-month treatment: a bivariate random effect meta-analysis. Pharmacopsychiatry. 2010;43(3):86-91.

74. Weinmann S, Roll S, Schwarzbach C, Vauth C, Willich SN. Effects of Ginkgo biloba in dementia: systematic review and meta-analysis. $B M C$ Geriatr. 2010;10:14.

75. Ihl R, Tribanek M, Bachinskaya N; GOTADAY Study Group. Efficacy and tolerability of a once daily formulation of Ginkgo biloba extract EGb 761(R) in Alzheimer's disease and vascular dementia: results from a randomised controlled trial. Pharmacopsychiatry. 2012;45(2): $41-46$.
76. van de Rest O, Geleijnse JM, Kok FJ, et al. Effect of fish-oil supplementation on mental well-being in older subjects: a randomized, doubleblind, placebo-controlled trial. Am J Clin Nutr. 2008;88(3):706-713.

77. Freund-Levi Y, Eriksdotter-Jönhagen M, Cederholm T, et al. Omega-3 fatty acid treatment in 174 patients with mild to moderate alzheimer disease: omegaAD study: a randomized double-blind trial. Arch Neurol. 2006;63(10):1402-1408.

78. Yurko-Mauro K, McCarthy D, Rom D, et al. Beneficial effects of docosahexaenoic acid on cognition in age-related cognitive decline. Alzheimers Dement. 2010;6(6):456-464.

79. Morris MC, Sacks F, Rosner B. Does fish oil lower blood pressure? A meta-analysis of controlled trials. Circulation. 1993;88(2):523-533.

80. Oudin A, Wennberg M. Fish consumption and ischemic stroke in Southern Sweden. Nutr J. 2011;10:109.

81. Scarmeas N, Stern Y, Mayeux R, Manly JJ, Schupf N, Luchsinger JA. Mediterranean diet and mild cognitive impairment. Arch Neurol. 2009;66(2):216-225.

82. Tangney CC, Kwasny MJ, Li H, Wilson RS, Evans DA, Morris MC. Adherence to a Mediterranean-type dietary pattern and cognitive decline in a community population. Am J Clin Nutr. 2011;93(3):601-607.

83. GuY, Brickman AM, Stern Y, et al. Mediterranean diet and brain structure in a multiethnic elderly cohort. Neurology. 2015;85(20):1744-1751.

84. Valls-Pedret C, Sala-Vila A, Serra-Mir M, et al. Mediterranean diet and age-related cognitive decline: a randomized clinical trial. JAMA Intern Med. 2015;175(7):1094-1103.

85. Huntley JD, Gould RL, Liu K, Smith M, Howard RJ. Do cognitive interventions improve general cognition in dementia? A meta-analysis and meta-regression. BMJ Open. 2015;5(4):e005247.

86. Cotman CW, Berchtold NC, Christie LA. Exercise builds brain health: key roles of growth factor cascades and inflammation. Trends Neurosci. 2007;30(9):464-472.

87. Groot C, Hooghiemstra AM, Raijmakers PG, et al. The effect of physical activity on cognitive function in patients with dementia: a meta-analysis of randomized control trials. Ageing Res Rev. 2016;25:13-23.

88. Diamond K, Mowszowski L, Cockayne N, et al. Randomized controlled trial of a healthy brain ageing cognitive training program: effects on memory, mood, and sleep. J Alzheimers Dis. 2015;44(4):1181-1191.

89. Ngandu T, Lehtisalo J, Solomon A, et al. A 2 year multidomain intervention of diet, exercise, cognitive training, and vascular risk monitoring versus control to prevent cognitive decline in at-risk elderly people (FINGER): a randomized controlled trial. Lancet. 2015;385(9984):2255-2263.

90. Lau AL, McKenna K, Chan CC, Cummins RA. Defining quality of life for Chinese elderly stroke survivors. Disabil Rehabil. 2003; 25(13):699-711.

91. Buck D, Jacoby A, Massey A, Ford G. Evaluation of measures used to assess quality of life after stroke. Stroke. 2000;31(8):2004-2010.

92. The World Health Organization Quality of Life assessment (WHOQOL): position paper from the World Health Organization. Soc Sci Med. 1995;41(10):1403-1409.

93. Park JH, Kim BJ, Bae HJ, et al. Impact of post-stroke cognitive impairment with no dementia on health-related quality of life. J Stroke. 2013;15(1):49-56.

94. McCullagh E, Brigstocke G, Donaldson N, Kalra L. Determinants of caregiving burden and quality of life in caregivers of stroke patients. Stroke. 2005;36(10):2181-2186.

95. Rigby H, Gubitz G, Eskes G, et al. Caring for stroke survivors: baseline and 1-year determinants of caregiver burden. Int J Stroke. 2009;4(3):152-158.

96. Ankolekar S, Renton C, Sare G, et al; ENOS Trial Investigators. Relationship between poststroke cognition, baseline factors, and functional outcome: data from "efficacy of nitric oxide in stroke" trial. J Stroke Cerebrovasc Dis. 2014;23(7):1821-1829.

97. Scholte op Reimer WJ, de Haan RJ, Rijnders PT, Limburg M, van den Bos GA. The burden of caregiving in partners of long-term stroke survivors. Stroke. 1998;29(8):1605-1611. 
98. Cupidi C, Realmuto S, Lo Coco G, et al. Sleep quality in caregivers of patients with Alzheimer's disease and Parkinson's disease and its relationship to quality of life. Int Psychogeriatr. 2012;24(11): $1827-1835$.
99. Hogan DB, Bailey P, Black S, et al. Diagnosis and treatment of dementia: 5. Nonpharmacologic and pharmacologic therapy for mild to moderate dementia. CMAJ. 2008;179(10):1019-1026.

\section{Publish your work in this journal}

Vascular Health and Risk Management is an international, peerreviewed journal of therapeutics and risk management, focusing on concise rapid reporting of clinical studies on the processes involved in the maintenance of vascular health; the monitoring, prevention and treatment of vascular disease and its sequelae; and the involvement of metabolic disorders, particularly diabetes. This journal is indexed on PubMed Central and MedLine. The manuscript management system is completely online and includes a very quick and fair peer-review system, which is all easy to use. Visit http://www.dovepress.com/ testimonials.php to read real quotes from published authors.

Submit your manuscript here: http://www.dovepress.com/vascular-health-and-risk-management-journal 